\title{
Improving the seismic resilience of housing in developing countries: time to transform local government building departments
}

\author{
Andrew Charleson ${ }^{1}$, Karyadi Kusliansjah" ${ }^{2, *}$, and Pele Widjaja ${ }^{2}$ \\ ${ }^{1}$ Architecture Department, Parahyangan Catholic University, Jl.Ciumbuleuit 94, Bandung, 40141, Indonesia. \\ ${ }^{2}$ Architecture Department, Parahyangan Catholic University, Jl.Ciumbuleuit 94, Bandung, 40141, Indonesia.
}

\begin{abstract}
Mitigation should be the key component of DRR in the context of seismic-resistant building construction, and more specifically - housing construction, in developing countries. Although this paper is relevant to many countries some emphasis is given to the situation in Indonesia. Mitigation, the outcome of which is safer buildings, is little more than an idea at present. It is often ignored in favor of easier DRR activities which while commendable, ignore the primary problem - unsafe buildings. After a review of the current situation regarding mitigation of building earthquake damage which highlights an almost total lack of action, the paper reviews recent suggestions to improve what is a very bleak situation. Then some recent drivers for change are explored. They indicate that now is the time to begin making positive changes in local government building departments and the broader building industry. The paper then discusses several examples of where some real progress is being made before concluding with suggestions for ways forward. It is hoped that future papers addressing this topic will be more about reporting on positive, practical actions than offering suggestions.
\end{abstract}

\section{Introduction}

The objective of this paper is to place more emphasis on achieving safer buildings as part of Disaster risk reduction (DRR). DRR, especially when concerned with seismic risk, comprises many different components, programs, and activities. They range from assessing the hazard of existing buildings within at-risk communities to education programs informing school children what they should do in the event of an earthquake. Unfortunately, almost all DRR initiatives overlook the primary overarching problem. That is, many, if not most existing or new buildings in developing countries have not been designed or built to be earthquake resistant and therefore present a significant hazard to live during a moderate or more massive earthquake. Numerous authors have highlighted this situation in their own countries, sometimes noting the need for retrofitting to reduce the loss of life. However other authors have pointed out that retrofitting is relatively very expensive and beyond the financial means of most. They have concluded that the best approach in the future is to concentrate on new construction. By improving the seismic safety of new construction and especially housing, typically at a cost far less than that of retrofitting, at least seismic vulnerability will not continue to increase. Eventually, most aging construction will be replaced in urban renewal programs before being affected by a damaging earthquake. Where this occurs, there is the opportunity for incrementally reducing risk over many decades. As discussed later in the paper the consistent achievement of seismically-safe housing involves a cultural change within the building industry. All levels from national government to homeowners have to be open to education and change if the current dire situation is not to be perpetuated and even worsened. Safe construction, as part of sustainable development, will reduce human and other losses from earthquakes and reduce poverty. This outcome needn't be incorporated within some DRR framework but can be considered as just wise and sensible building construction practice.

\section{Current situation}

This section explores through a wide range of available literature the seemingly almost zero enhancement of building safety in recent years. Studies with an international scope and research focused on individual countries very much tell the same story that seismically dangerous construction continues to be the norm.

With respect to international overviews of DRR achievements the lack of progress towards safer construction is often not mentioned explicitly but is apparently due to its absence. For example, in its review of DRR achievements (UNISDR, 2016) there are no reports of any country making progress towards safer

*Corresponding author: karyadi@unpar.ac.id 
new construction. Another UNISDR publication (2017) gives plenty of valuable advice regarding what is required for more resilient building stock, and although some case studies are presented, none show how local city building departments are making a difference. Instead, the emphasis is on how local government leaders can improve the culture of resilience instead on the concrete steps to be taken by the local government to improve the likelihood of safer construction. A similar finding emerges from Peek et al. (2016).

Another international review of urban risk focusing on Asian countries highlights problems rather than progress (Rajib Shaw et al., 2016). City governments must play critical roles in reducing risk, including from unplanned, uncontrolled and rapid urbanization but legislative structures can create difficulty. For example, in Indonesia, there are eight levels of laws and regulations with the bottom three comprising Ministerial regulation, Provincial regulation, and City/district/municipality regulation. Local government authorities do issue specific local regulations, but less than half have local building regulations in place, and even if they do they may not be consistent with national regulations

Given local governments' power and responsibility to protect residents and their assets, enhancing a city's resilience must be an integral part of planning and investment. Yet even in Dhaka, the world's most seismically vulnerable city according to the Earthquake Risk Index (EDRI) most emphasis on DRR in Dhaka is on the post-earthquake response! A constant theme emerges of owners and builders not considering earthquakes as a potential hazard, and the almost universal situation of costs being more important than building safety. According to Rajib Shaw et al., owners request lower standards to reduce construction costs, and this is compounded by the fact that most workers don't know about codes/guidelines.

Several examples follow of national and local examples of DRR not impacting on the provision of safer housing. They are chosen from a significant number of other published papers and reports. To begin with, when evaluating the seismic risk in Bandung, primarily determined by the nearby Lembang fault, researchers ascertained that $50 \%$ of the housing stock needed retrofitting (Ameridyani et al., 2015). Half of those building new houses didn't consider the seismic hazard at all, and in fact, there appears to be an attitude of denying the hazard and consequently their own vulnerability. Adding to this problem of lack of community awareness are those of poverty and inadequate building standards. This finding was collaborated by Surahman (2000) who determined that only $62 \%$ of Bandung buildings were adequately framed. This percentage seems rather high, especially in the light of the situation in Peru which found that only $8 \%$ of public school infrastructure complied with seismicresistant design codes (GFDRR 2014).

According to a review of seismic design in Pakistan, corruption was found to nullify building regulations. The vulnerability of existing construction was acknowledged with a recommendation to improve new construction rather than focusing upon retrofit (David Bonowitz, 2015)

In Bogata, $60 \%$ of new homes are of 'informal origin' - outside the national code and any regulatory control (Nacif Hartley et al. 2017). Code requirements are not followed so confined masonry is almost unreinforced masonry. Common structural problems include: "steep hillsides; low-quality hollow bricks; not enough walls in both directions; no foundations under interior walls; no vertical continuity of columns and walls; rc slab and walls cantilever at the front of the house; and quality of construction issues." Also noted are the extensive and detailed packages required for building permits; that mitigation should be focused on all the buildings in a block to prevent vulnerable buildings affecting safer buildings, and the problem of making people aware of the risks their houses pose to them.

When discussing implementation of the Iranian National Building Code, M Ghafory-Ashtiany et al (2017) outline a whole list of problems, including: "Designers and contractors try to satisfy building owners and don't comply with the code; only architectural plans are inspected by municipalities; poor construction quality due to few inspections; and no control of quality of building materials, or qualifications of workers and technicians.

\section{Suggestions for ways forward}

This section summarizes various ideas and visions for implementing a program to improve building compliance and achieve safer buildings. That building compliance saves lives and non-compliance results in more deaths, casualties and damage can be demonstrated by comparing the outcomes after two different earthquakes of similar size (WB/GDFRR 2015). This document presents a vision for transforming a country's whole building sector, especially local building departments. It sees a building department managing the core functions of building technical assistance including plan review, site inspection, permitting and enforcement, and this is what is new: "with the goal of facilitating voluntary compliance." Advisory services will be provided to informal sector builders. To achieve this vision local building departments' will need to modify their mission statements to become less self-serving and concentrate and take pride in helping their cities, be safer during an earthquake that one day will strike. It is also assumed that there will be knowledge sharing between building departments and means to help them improve efficiency and to measure their effectiveness against their goals.

Such a program to improve building resilience can't be left just to local building departments. Partnerships with other organizations are required. These include: "professional associations and societies related to codes of practice; leading academic institutions in engineering, architecture, urban planning, construction, and building technology; accredited training institutions for the construction labor force; bodies responsible for licensing procedures for building professionals; and implementers of quality control processes for building materials. In 
particular, partners will be sought to help develop and enforce modern compliance tools for improved information and communications systems aimed at risk management, building practitioners' certification, private third-party accreditation to provide review and inspections, and the use of insurance mechanisms to augment building control." This is a grand vision, but such a large-scale program may not happen for many years due to lack of funding, so what can be done now?

Other organizations are also seeking to develop approaches to improve building safety. For example, BuildChange (2014) has many excellent suggestions although made in the context of the seismic retrofit of the housing.

Incentives are likely to be needed for all stakeholders for changes proposed to the construction industry. ADB (2016) report suggested different possible incentives for building owners. Under urban planning initiatives "free advice on design and construction and/or retrofitting of housing in the hazard-prone area resulting in disasterresilient housing [and] free or low-cost building materials and tools resulting in compliance with building codes" is suggested. Of course incentives for government officials at different levels also need to be considered.

UNISDR (2013) emphasizes similar points: greater priority should be put on sharing and disseminating scientific information and translating it into practical methods that can readily be integrated into policies, regulations and implementation plans concerning disaster risk reduction, education on all levels, comprehensive knowledge management, and involvement of science in public awareness-raising, media communication, and education campaigns should be strengthened. Regarding building regulations in developing countries, for homes and other small buildings, the best default approach is to educate rather than regulate, leaving regulatory construction engineers and planners to focus their efforts on relatively few hightraffic public buildings.

A similar approach to education as an alternative to or in conjunction with regulation is advocated by Charles Kenny (2009). In discussing the costs, benefits, and institutions of disaster risk reduction in developing countries, he suggests that "cheap and simple approaches to mitigation need to be developed and put in place. In environments where capacity is low, and the risk of corruption is large, this suggests a radically different approach than adopting US or EU regulations and codes en mass. There has been considerable research and development regarding comparatively simple building practices that can reduce the risk of collapse - governing issues such as window and door size and placement, wall width and building heights. Such approaches have the advantage of being comparatively straightforward for even unskilled labor to implement, and comparatively straightforward for unskilled and ex-post evaluation. This not only reduces the burden on regulatory agencies but also allows for simple and independent civil society review of the performance of the regulator itself."

Tatsuo Narafu et al. (2010) observe that builders of non-engineered houses have limited capacity to absorb technical knowledge. Therefore they need to be given simple rules to follow. In parallel, house owners are given information, so they are able to undertake supervision. In developed countries "we expect diffusion of technologies through administrative procedures such as building permits and supervision by officials" so the authors question how something like this might operate in developing countries? How might building departments become 'resource centers' for homeowners undertaking a building project? Might this be possible? The authors' recommendations can be summarized as follows:

1. Provide motivation and justification for seismic design based on seismicity.

2. Develop technical solutions based upon an understanding of the seismic performance of local building types and worker capability.

3. Disseminate technologies to all stakeholders including owners and government officials.

4. Provide the following support to homeowners: economic support, social support for legal and administrative purposes and lever off any other community upgrading initiatives that will usually address improving day-to-day living conditions.

Rajib Shaw et al. (2016) suggest that city governments need to outsource some activities to private agencies. They state: "it is awareness and the motivation of homeowners, builders, and workers dealing directly with homeowners that dictate compliance with building codes and standards." They recommend that inspection systems are more orientated toward technical compliance. They conclude that codes have minimal effect in the field; earthquake-safe guidelines and codes should be more straightforward and disseminated widely to homeowners, builders, and artisans; awareness-raising is essential; quality control or inspection is needed from local authorities in order to achieve good construction practices; a certification program will help ensure worker quality; and experts need to communicate with workers to reduce the knowledge gap between them.

The authors make a very valid point when they mention how local authorities need encouragement, empowerment, and support in order to be effective in enforcement. NGOs, community-based organizations and private sectors should work with local governments to devise innovative strategies and incentive mechanisms to make change possible. They also point out that there needs to be an entry point for DRR in the urban context, where DRR needs can be linked with daily priority issues. There also needs to be specific change agents to motivate and lead efforts to make changes. In their view three vital components preceded the development of a new DRR program: first, individual level awareness and concern regarding earthquake risk. Secondly, action on the part of the person or those concerned. Thirdly, external support to be forthcoming for the efforts of the concerned, and finally, support from an authoritative leader was the final common action that helped enact change. Individuals within organizations who take the initiative are the key.

Other suggestions from an Iranian perspective are offered by, M Ghafory-Ashtiany et al. (2017). They 
believe that raising public awareness of the risk of living in vulnerable buildings will improve code compliance. This would include the issue of "ownership-technical certificates" for new buildings which would cover the adequacy of construction materials and procedures in accordance with the code standards. They also suggest promoting safe housing as a 'civil right'; applying 'economic concepts' to justify seismic safety; developing a tool to assess the seismic safety of buildings for use in a ranking system to help buyers differentiate between quality of buildings; an earthquake insurance program; updated codes relevant to local conditions; enforcement systems more resilient against corruption; and finally, more transparency and involvement of legally qualified designers and contractors on the basis of technical competency.

\section{Current pressures for improving seismic resilience of housing}

In the last few years there have been several developments that have promoted the importance of mitigation in DRR, and in particular, achieving safer buildings. The first notable change of emphasis away from the response to place more emphasis upon mitigation or resilience arose from the Third UN world conference on disaster risk reduction in 2015, Sendai, Japan (UNISDR 2015). The conference outcome included 'priorities for action,' namely :

1. Priority 1: Understanding disaster risk.

2. Priority 2: Strengthening disaster risk governance to manage disaster risk.

3. Priority 3: Investing in disaster risk reduction for resilience.

4. Priority 4: Enhancing disaster preparedness for effective response and to "Build Back Better" in recovery, rehabilitation, and reconstruction."

All these priorities are relevant to this paper. As an example of what is proposed, Priority 1 (g) states "To build the knowledge of government officials at all levels, civil society, communities and volunteers, as well as the private sector, through sharing experiences, lessons learned, good practices and training and education on disaster risk reduction, including the use of existing training and education mechanisms and peer learning". Priority 2 includes: "(c) To carry out an assessment of the technical, financial and administrative disaster risk management capacity to deal with the identified risks at the local and national levels; and (d) To encourage the establishment of necessary mechanisms and incentives to ensure high levels of compliance with the existing safety-enhancing provisions of sectoral laws and regulations, including those addressing land use and urban planning, building codes, environmental and resource management and health and safety standards, and update them, where needed, to ensure an adequate focus on disaster risk management; (e) To develop and strengthen, as appropriate, mechanisms to follow up, periodically assess and publicly report on progress on national and local plans; and promote public scrutiny and encourage institutional debates, including by parliamentarians and other relevant officials, on progress reports of local and national plans for disaster risk reduction; (f) To assign, as appropriate, clear roles and tasks to community representatives within disaster risk management institutions and processes and decisionmaking through relevant legal frameworks, and undertake comprehensive public and community consultations during the development of such laws and regulations to support their implementation".

The second source of momentum working towards more resilient buildings is a growing awareness of the fundamental human right of people to live safely. Action Aid is promoting this approach which is based upon a human rights awareness of resilience (Action Aid 2016). As far as mitigation actions are concerned, it gives the following example of 'resilience building activities': "Support governments to ensure that all tradesmen are trained in earthquake-proof building practices."

For an example of a national initiative in improving the resilience of housing, Tatsuo Narafu (Ed. (2016) tells of a February 2016 decree issued by the Indonesian Minister of Public Works and National Housing that includes technical guidelines for non-engineered housing including plans of nine house prototypes which meet the provisions of the guideline.

\section{Examples of effective initiatives}

As mentioned previously, there are very few examples from developing countries where efforts to improve seismic resilience involve local government initiatives. But the following three case-studies show how progress might be made in other situations. Tatsuo Narafu (2016) outlines the experience in Central Java following the 2006 M 6.3 earthquake. 5,000 lives were lost, 154,000 houses were destroyed, and 260,000 sustained structural damage. Soon after the disaster, the local government announced and implemented significant initiatives and critical principles for housing reconstruction. These principles included, i) ensuring structurally safe housing reconstruction; ii) aiming for the reconstruction of permanent housing rather than temporary shelters; iii) providing direct cash transfers to residents to rebuild their homes; and iv) limiting engagement with international partners by promoting locally available human resources. The cash transfers for residents were made based on compliance with building permit procedures and with the technical guideline called "Key Requirements." Appropriate for simple single-story houses, these consisted of three components: a) quality of building materials; b) dimensions of structural members; and c) appropriate joints of structural members. Assistance was provided by the Japanese International Cooperation Agency (JICA), leading engineers and university staff and personnel from other Indonesian institutes. Training regarding the Key Requirements was undertaken through designated district building administration offices and through their formal building-permitting process, as well as by supporting information campaigns that utilized a wide range of dedicated tools, including illustrated posters, 
booklets, and seminars/training for housing owners, workers and local government officials. To improve sustainability and to increase the impacts at the national level, JICA assisted the Ministry of Public Works to develop standard models of the ordinance for provincial governments, based on the experience of the reconstruction in Central Java. Provincial governments also requested assistance with outreach training programs for communities and local government officials.

This is an example of how vulnerable non-engineered housing became resilient and leveraged existing building administration, the building-permitting process and the use of clear technical guidelines. Tatsuo Narafu concludes; "This experience also highlights an original idea and a potentially useful role for established building-code administrations in promoting awareness and improving the quality and resilience of nonengineered houses through a broader focus, one that includes education and guidance rather than simply police enforcement."

Lessons learned from past earthquakes were applied to the new construction in Iran after two damaging earthquakes in 1981. The new, economical and straightforward subsequent improvement of structural connections were considered to have reduced damage during the 1998 earthquake (Ibrion M et al. 2015). However, the authors note the need for a culture of resilience develops at all levels of society for useful long-term improvement to occur.

The final case study is from Nepal where the National Society for Earthquake Technology's (NSET) Building Code Implementation Program in Nepal (BCIPN) began in 2007 (S Shrestha et al. 2017). This initiative responded to local municipalities' lack of appropriate mechanisms and capacities to implement the building code. For example, two engineers were expected to service approximately 400 new building permits per year; there was no mechanism for site verifications of drawings leading to most buildings designed and built without regard for seismic safety. In addition to these problems there was no specific enforcement framework in municipalities; a considerable variation in progress and accountability of staff; a need for municipalities to communicate and mobilize masons and building owners; a lack of political will; a lack of community representatives on boards of municipalities to increase the will to improve enforcement; some municipal engineers designing buildings with conflicts of interest; the public and untrained masons unaware of the Building Code and earthquake-resistant construction techniques, and a national database of registered designers and supervisors is needed so designers can design in any city in Nepal.

According to the authors "mobile clinics didn't help, but the breakthrough was the introduction of a licensing system for local builders and masons. Registration was only possible after four-day training in the earthquakesafe building. The system was strengthened by a reward and punishment system." Masons received prizes and certificates while homeowners faced penalties and masons risked being suspended. However, the importance of changing the risk perception of people should not be underestimated (N Shrestha et al., 2017). A survey of 40,000 people was undertaken, and almost half believed their house was not safe in an earthquake but were reluctant to do anything about it. 50\% didn't know about earthquake-safe construction nor had they heard about the National Building Code.

Significant changes were introduced. Given the difficulty of structurally checking all buildings, the Nepal Building Code Mandatory Rules of Thumb were simplified to five rules for each of RC and masonry buildings. Now homeowners have to be present when registering a building permit and are briefed on requirements. They sign along with the mason that compliance has occurred and the municipality makes site visits. Now $80 \%$ of buildings in one Municipality follow the code and other municipalities are learning from it. Other changes include how permit fees are charged and increased; during permit registration the owner and contractor are given earthquake resistant construction information; contractors are licensed after a four day training period; municipal officers visit the site and check foundation level, plinth level, superstructure level and after construction; some monitoring is given to Ward level disaster risk management committees to supplement municipality human resources. Finally, a simple checklist for basic design checking by municipal authorities has been implemented. Designers first complete the list and if specific criteria are not met redesign is required.

During the implementation of this program the following lessons were learnt: accountability of municipal officials, supervisors, masons/ contractors need to be improved by preparing an enforcement framework; the municipality should mobilize all stakeholders; municipal engineers should not be engaged in the preparation of drawings; only use trained masons; owners need to be made aware and involved in the process; a construction monitoring mechanism is needed; an improved building permit system introduced, and minimum qualifications for designers of different building types.

This Nepalese case study could be the most useful for other regions to learn from. However, it must be noted that the program depended upon significant funding from USAID. There was 50 staff involved in the program.

\section{Where to from now?}

By now it will be clear how complex and challenging it is to change current practice and very entrenched institutional and personal cultures in order to achieve seismically-safe housing. Of all the ways forward those learned from the Nepalese experience may be the most applicable. The literature, as seen above, doesn't lack suggestions or ideas, and unfortunately, this last section of the paper perpetuates this situation. But now the intent is to try to make some observations and further suggestions that might be implemented on the ground. They are not offered in any particular order, but it is 
hoped that they will stimulate further discussion leading to action.

One way to begin is with a pilot program. A midsized municipality could be chosen or invited to participate. After a period of raising risk awareness, the targeting the entire of community the municipality's building department would be tasked to introduce many of the significant improvements above to ensure safe construction. A change to the institution's mission statement would then have to involve all types of incentives to motivate participants to undergo training and make changes to their official activities.

Other professions should be requested to support the municipal officers. Perhaps academic staff from engineering and architecture schools could focus their 'community service' time on this project. Local consultants should also be consulted to seek their assistance, and all stakeholders, including the general public, should be informed about the changes and their opinions and comments listened to.

One or more mitigation champions should be

Identified in stakeholder institutions and adequately supported from levels above them as well as other bodies in the building industry. One of the key aspects is that of leadership. Effective and even inspirational leadership is required to institute the proposed changes.

The informal housing sector should be engaged. This might be through community meetings or facilitated through building supply outlets. Perhaps there might be a more effective means of communication, including social media, but the power of television should not be underestimated.

In order to make such a program as sustainable as possible additional necessary funding would best be provided from local or at least national sources. The cement and reinforcing steel industries are going to benefit if safer construction is achieved. Also, one of the causes of the current unsafe situation is the wrong application of these building materials. Might some of these companies be prepared to partner these changes within the building industry? By so doing they will also be investing in their futures. After the devastating Canterbury earthquakes, New Zealand, in 2011/2012 new buildings rely upon structural steel framing.

There may be professional bodies and private companies who in some way will also benefit from a safer built environment and are prepared to lend their names and resources to an improved building regulatory system. These need to be identified and invited to participate.

One of the key aspects is that of leadership. Ideally, it can be provided by a so-called mitigation champion at an appropriate level in a local government building department.

\section{Conclusions}

The paper argues that achieving seismic-resistant building construction should be a key component of DRR. A review of current DRR practice highlights an almost total lack of action towards achieving earthquake- resistant buildings. Some recent drivers for change are explored that suggest now is the time to begin making positive changes in local government building departments and the broader building industry. Several examples illustrate real progress being made, and the paper suggests other ways forward to protect communities from future human and material losses from earthquakes.

\section{References}

1. UNISDR, Disaster risk reduction achievements 2016: good practices, tools, and initiatives supported by the DIPECHO programme, UNISDR, (2016)

2. UNISDR, How to make cities more resilient: a handbook for local government leaders, UNISDR,(2017)

3. Peek, Ryder, Moresco, and Tucker, Disaster risk reduction strategies in earthquake-prone cities, Springer International Publishing, Switzerland, (2016)

4. Rajib Shaw, Atta-ur-Rahman, Akhilesh Surjan, and Gulsan Ara Parvin, Urban risk, city government and resilence in Asia, BH, Elsevier,(2016)

5. Ameridyani et al., Enhancing community awareness towards potential earthquake of Lembang Fault: Lessons learned from the Kathmandu Valley earthquake, (2015)

6. Adang Surahman, Earthquake vulnerability evaluation of buildings in Bandung municipality, 12WCEE, (2000)

7. Bonowitz, David, Seismic design in Pakistan: the building code, bylaws, and recommendations for earthquake risk reduction, UNDP.,(2015)

8. GFDRR, Protecting School Infrastructure Against Earthquake Risks in Peru, GFDRR,(2014)

9. D Nacif Hartley, M L Blaisdell, J Caballero and E Hausler Strand Seismic evaluation and retrofit for reducing the vulnerability of housing in Colombia: development and implementation Paper No 4200 17WCEE,(2017)

10. M Ghafory-Ashtiany et al., Review of the implementation of Iranian National Building Code: current challenges and future directions Paper no. 1396, (2017)

11. Thomas Moullier, Building regulation for resilience: managing risks for safer cities, World Bank and GRDRR,(2015)

12. BuildChange, Seismic retrofit of housing in postdisaster situations: basic engineering principles for development professionals, Build Change and USAID,(2014)

13. UNISDR Scientific and technical advisory group, Using science for disaster risk reduction UNISDR,(2013)

14. Kenny, Charles, Why do people die in earthquakes? the costs, benefits, and institutions of disaster risk reduction in developing countries, (2009) 
15. Tatsuo Narafu et al., A proposal for a comprehensive approach to safer non-engineered houses, Journal of Asian Architecture and Building Engineering, 322 pp, (2010)

16. Rajib Shaw, Atta-ur-Rahman, Akhilesh Surjan, and Gulsan Ara Parvin, Urban risk, city government and resilence in Asia,(2016)

17. UNISDR, Third UN world conference on disaster risk reduction 14-18 March 2015, Sendai, Japan a number of 'priorities for action UNISDR,(2015)

18. (ActionAid, Resilence building: a guide to flood, cyclone, earthquake, drought and safe schools programming version 1, ActionAid International, (2016)

19. Tatsuo Narafu (Ed.), Towards resilient nonengineered construction: a guide for risk-informed policymaking, UNESCO.,(2016)

20. Ibrion $\mathrm{M}$ et al., Earthquake disaster risk reduction in Iran: lessons and 'lessons learned' from three large earthquake disasters: Tabas 1978, Rudbar 1990, and Bam 2003,(2015)

21. S Shrestha, R Mul, S P Lama, et al., Improving building permit system for building code enforcement: applicable for medium-sized municipalities Paper 2315,(2017)

22. N Shrestha, A M Dixit, et al., Changing risk perception of people: a key for enhancing building code compliance Paper no. 1862

23. Bonowitz, David, UNDP Seismic retrofit of housing in post-disaster situations: basic engineering principles for development professionals, (2015)

24. D Nacif Hartley, M L Blaisdell, J Caballero, and E Hausler Strand, Seismic evaluation and retrofit for reducing the vulnerability of housing in Colombia: development and implementation 17WCEE Paper No 4200, (2017) 